\title{
As irmãs siamesas fake news e pós-verdade expandidas nas deepfakes
}

\author{
Lucia Santaella'
}

Resumo: A partir de 2016 , a expressão fake news e sua parceira, pós-verdade, passaram crescentemente a tomar conta das mídias noticiosas e interpretativas, com muitas matérias publicadas sobre o tema, ganhando, inclusive, as discussões mais detalhadas e bem-informadas da pesquisa acadêmica. Nesse contexto este dossiê pretende apresentar esse tema nas repercussões que tem obtido em algumas publicações selecionadas com o objetivo de preparar o leitor com informações preliminares à leitura dos artigos sobre deepfake que se apresentam neste número da TECCOGS. Infelizmente ainda não contamos no Brasil com livros sobre deepfake, o mais jovem rebento das fake news. Vem daí a relevância deste número que toma a dianteira na busca de uma primeira sistematização sobre essa questão que promete trazer consequências ainda mais nefastas para o equilíbrio social do que as fake news.

Palavras-chave: Fake news. Pós-verdade. Deepfake.

I Lucia Santaella é pesquisadora IA do CNPq, professora titular da PUC-SP. Publicou 5I livros e organizou 24, além da publicação de mais de 400 artigos no Brasil e no exterior. Recebeu os prêmios Jabuti (2002, 2009, 20II e 20I4), o prêmio Sergio Motta (2005) e o prêmio Luiz Beltrão (2010). ORCID: orcid.org/0000-0002-068I-6073. CV Lattes: lattes.cnpq.br/74278546577I943I. E-mail:1braga@pucsp.br. 


\title{
The siamese sisters fake news and post-truth expanded in deepfakes
}

\begin{abstract}
From 2016 on, the expression fake news and its partner, post-truth, have increasingly taken over the news and interpretive media, with many articles published on the subject, even gaining the more detailed and well-informed discussions in academic research. This dossier intends to present this theme in the repercussions it has obtained in some selected publications with the objective of preparing the reader with preliminary information for the articles about deepfake that are presented in this issue. Unfortunately, we still don't have books in Brazil about deepfake, the youngest offspring of fake news. Hence the relevance of this issue, which takes the lead in the search for a first systematization of this subject, which promises to bring even more disastrous consequences for social balance than fake news.
\end{abstract}

Keywords: Fake news. Post-truth. Deepfake. 
As deepfakes são uma extensão, em peças de áudio e vídeo, das fake news, estas quase sempre verbais. Ambas estão associadas às multifacetadas questões relativas à pós-verdade. Esta expressão ganhou notoriedade a partir de 20I6, quando se deram as surpreendentes vitórias de Trump nas eleições dos Estados Unidos e do plebiscito Brexit, no Reino Unido. Tanto uma quanto a outra foram consideradas batalhas vencedoras devido à proliferação de notícias falsas que correram pelas redes digitais e que impulsionaram o voto de eleitores mal-informados e, consequentemente, crédulos em relação às enxurradas de mensagens politicamente distorcidas que receberam.

Logo depois, em 20I8, deu-se o escândalo do Cambridge Analytica, uma empresa inglesa de análise de dados. Um de seus pesquisadores havia desenvolvido um aplicativo de extração de dados pessoais e obtido autorização do Facebook para sua aplicação. Então, pesquisas revelaram que 50 milhões de dados de usuários foram vendidos pelo pesquisador à Cambridge Analytica que tinha Trump como cliente. A influência que isso teve nas eleições presidenciais foi desvendada por jornalistas investigadores, redundando, por fim, na falência da empresa e no questionamento do Facebook acerca da permissão de que dados privados de usuários sejam repassados a quaisquer interesses externos. Os fatos acionaram o alerta quanto ao poder político das notícias falsas e, desde 20I8, o termo "fake news" passou a tomar conta das mídias noticiosas e interpretativas, com muitas matérias publicadas sobre o tema, ganhando, inclusive, as discussões mais detalhadas e bem-informadas da pesquisa acadêmica.

O objetivo deste dossiê é apresentar o tema nas repercussões que tem obtido em algumas publicações selecionadas, de modo a preparar o leitor com informações preliminares à leitura dos artigos que se apresentam neste número da TECCOGS. Já há um bom número de autores tanto brasileiros quanto estrangeiros, cujas obras obtiveram tradução em português, que se dedicaram ao assunto, quase sempre ligando as fake news à sua irmã siamesa, a pós-verdade. Infelizmente ainda não contamos no Brasil com livros sobre deepfake, o mais jovem rebento de ambas. Vem daí a relevância deste número que toma a dianteira na busca de uma primeira sistematização sobre essa questão que promete trazer consequências ainda mais nefastas para o equilíbrio social do que as fake news. 
Para a consecução do objetivo pretendido, segue-se a breve discussão do estado da arte limitado a livros, no caso das fake news, com a finalidade de abrir caminho para os artigos sobre deepfake, presentes neste número, que irão tratar devidamente de algumas das principais preocupações relativas a essa nova forma de enganação. A discussão abaixo buscará tomar uma linha cronológica de modo a evidenciar a evolução das preocupações, especialmente depois que as fake news se tornaram no Brasil objetos de investigação judicial.

Não deixa de ser de interesse que Serva (200I) tenha publicado, avant la lettre, um livro sobre jornalismo e desinformação já que a desinformação se tornaria o tema-chave relativo a fake news a ponto de alguns preferirem a palavra desinformação em lugar de fake news. Mas foi a partir de 2016 que a "pós-verdade" começou a atrair os acadêmicos, por ter sido escolhida pelo Dicionário Oxford como a palavra do ano, cujo verbete lhe dava o seguinte significado: "relativo a ou que denota circunstâncias nas quais fatos objetivos são menos influenciadores na formação da opinião pública do que apelos à emoção ou à crença pessoal" (GI, 20I6).

Assim sendo, já em 20I7, apareceram duas publicações no Brasil com a questão da pós-verdade em seus títulos. Assinado por Dunker et al. (20I7), o livro Ética e pós-verdade, por ter sido escrito antes que a questão das fake news tivesse explodido, está mais voltado para os jogos interpretativos da expressão "pós-verdade", quase sempre preocupados com o significado do prefixo "pós", inclusive nas correlações com a pós-modernidade (ibid. p. 8, 95). Trata-se de uma correlação infeliz, em primeiro lugar, porque perde o foco do sentido situado da pós-verdade no contexto das fake news. Em segundo lugar porque a relação com a pós-modernidade exigiria um estudo muito bem fundamentado da complexidade multifacetada desse conceito na sua evolução desde os anos ig80 até os nossos dias.

A outra publicação de 2017 sobre pós-verdade voltou-se para a sua relação com a educação (Chates, org., 20I7). Os textos têm o mérito de colocar sob sua mira as transformações dos processos educacionais a partir da avalanche de informações veiculadas nas redes digitais e em que medida isso afeta a construção do conhecimento e da verdade e os procedimentos de formação. Embora apareça no título, o sentido situado de pós-verdade não é discutido no livro.

De fato, foi só a partir de 2018 que as publicações começaram a atacar as questões correlatas das formações de bolhas - também chamadas de câmaras de eco e vieses da confirmação - com as fake news e a pós-verdade, o que conduziu à constituição mais própria daquilo que chamo 
de sentido situado desta última (Ferrari, 20I8; Santaella, 20I8). Publicado no mesmo ano, o texto de D'Ancone (20I8) tem mais um caráter de denúncia, especialmente contra Trump, do que de pesquisa de escritos sobre o tema. Como parece ser de praxe, o autor retorna ao pretenso parentesco da pós-verdade com a pós-modernidade. Esta vê-se reduzida aos autores do pós-estruturalismo que, lamentavelmente, são pasteurizados sob o rótulo de construtivistas (ibid., p. 85). Além disso, o livro baseia-se em uma visão simplificada da verdade (p. I2I). Se, de fato, é necessário mantê-la, também é preciso considerar que, embora as mentiras possam ser absolutas, não há verdade absoluta, uma questão que não necessita ser discutida estritamente no campo do relativismo. Ainda de 2018 é o livro de Keyes que se dedica à discussão prolongada da mentira, revelando uma preocupação com a oposição entre mentira e honestidade como se a honestidade tivesse, por si só, um poder de combate contra o enxame de fake news.

O ano de 2018 foi a data das eleições presidenciais no Brasil, momento em que as correlações entre os três fatores (bolhas, fake news e pós-verdade) esquentaram, devidamente acompanhadas pela batalha travada contra a mentira, quase sempre de teor político, pelas instituições de checagem dos fatos, uma batalha travada não apenas contra a mentira humana, mas também contra a sua extensão nos bots.

Os bots, abreviação de robôs, são programas de software que executam repetitivamente tarefas automatizadas, pré-definidas. São insidiosos porque imitam comportamentos humanos. Lima (2018) nos informa que, por serem programados para espalhar informações muito mais rápido do que seres humanos conseguem fazer, as redes sociais são bombardeadas com as fake news, "causando um efeito dominó: quanto mais pessoas reais têm contato com a notícia falsa, mais elas acreditam que a informação é verídica, e acabam por compartilhá-la."

Pior do que isso, a falsidade tem o poder de se difundir "mais longe, mais rápido, mais profundamente e mais amplamente do que a verdade em todas as categorias de informação". Enquanto uma informação falsa necessita de aproximadamente Io horas para alcançar I500 usuários no Twitter, uma informação verídica precisa de 60 horas. Disso se conclui "que o fator humano é mais importante na disseminação de notícias falsas que os bots em si" (ibid.).

A partir dessas comprovações, fica claro que não pode haver outro meio de estancar a proliferação de fake news sem que haja leis que regulamentem o funcionamento das plataformas de redes sociais com rigor. A par desse meio, alguns pesquisadores, entre os quais me coloco, defendem que legislações apenas não são suficientes, mas é preciso também desenvolver programas educativos para e nas redes. 
A partir de 20I9, não é preciso sair do território brasileiro para constatar que as publicações sobre as fake news começaram a se multiplicar. É de 2019 o livro organizado por Barbosa, contendo uma diversidade de subtemas tais como o da credibilidade e confiança que prescindem da verdade e que estiveram nas bases da eleição de Bolsonaro (Bruno e Roque, 20I9). Ou então, a crítica de Bucci (20I9), em defesa do jornalismo ético, o qual implica constatar que "news não são fake - e fake news não são news". Ou ainda, a complexa discussão sobre a "liberdade de expressão ou dever de falar a verdade" (Macedo Júnior, 20I9). Depois de discutir os problemas envolvidos nesse dilema, Macedo chama atenção para os perigos das soluções pouco democráticas de projetos de lei que podem impor algum tipo de censura, o que pode também "representar uma nova ameaça ao ainda pouco consolidado pensamento nacional sobre a liberdade de expressão" (ibid. p. 83).

Se, de um lado, as redes sociais adicionam um ganho para a pluralidade informacional da esfera pública, de outro lado, elas produzem efeitos colaterais nefastos que desembocam em patologias sociais. "A propagação viral de discursos de ódio, de conteúdo racista e xenófobo, atinge não apenas os grupos ou indivíduos diretamente atacados, mas todos aqueles que nas sociedades abertas defendem a liberdade" (ABBOUD et al., 2018, p. I67). Entram, assim, em pauta os dilemas relativos a regular o ecossistema digital. Para começar, segundo os autores, "o grande desafio trazido pela proliferação aparentemente incontrolável dos discursos de ódio e das fake news nas redes sociais é encontrar soluções adequadas à instantaneidade da era digital, e não meras transposições de técnicas de aplicação do Direito que têm origem na era analógica e não oferecem soluções inteiramente satisfatórias" (ibid.).

No caso do Brasil, enquanto se dava o comprovado avanço promovido pelo marco civil da internet relativo à segurança e privacidade, a enxurrada de fake news acabou por se converter em questão judicial. A fonte geradora da perversão tinha sua proveniência no gabinete do ódio que se instalou no centro do poder. Vítimas desse ódio foram notoriamente mulheres jornalistas, em especial Patrícia Campos Mello, repórter especial da Folha de S. Paulo que se especializou no fenômeno da manipulação de narrativas em campanhas eleitorais, nos Estados Unidos, na Índia e no Brasil. Durante as eleições de 2018 no Brasil, Mello publicou uma série de reportagens sobre o financiamento do disparo em massa de notícias falsas em benefício do então candidato Jair Bolsonaro. A reação imediata foi vitimizar a jornalista em uma violenta campanha de difamação e in- 
timidação, tornando-se ela mesma objeto de fake news. Sua coragem no enfrentamento dessa batalha e em defesa da liberdade de expressão lhe valeu prêmios, inclusive, recentemente, na França. Em seu livro sobre "A máquina do ódio", Mello (2020) fez o relato dos bastidores desses eventos, funcionando como um manifesto que advoga a favor da liberdade da informação.

$\mathrm{O}$ ano de 2020 , avançando para 202I, foi pródigo em publicações que exploram a questão das fake news, fornecendo-nos um panorama multifacetado para compreender esse fenômeno e encontrar os caminhos mais eficazes para enfrentá-lo. Por exemplo, Cursino et al. (202I), no livro “Discurso e (pós) verdade", exploram a verdade e a pós-verdade nas suas relações com o discurso. Chegam, assim, bem perto da natureza semiótica das fake news. Faustino (2020), por sua vez, discute a liberdade de expressão no contexto das fake news, aliás, um limiar bastante difícil de ser estabelecido para a legislação das fakes news que não fira princípios de liberdade de expressão.

Era de se esperar que a área de Direito se visse diretamente interpelada pelos dilemas das fake news e pós-verdade. Não é casual que publicações sobre isso não cessem de aparecer. Rais (org., 20I8) apresenta um panorama interdisciplinar sob o carro-chefe do direito. Menezes (2020) enriquece o pensamento sobre regulação ao colocá-lo, com cuidados metodológicos, no contexto da modernidade. Na sua preocupação com a preservação dos valores democráticos, sugere a necessidade de um conceito original de "consenso paradigmático" nas sociedades pluralistas que, para isso, dependem de instituições sociais fortes que possam fazer frente às contingências das instabilidades informacionais. Por fim, Jorge et al. (202I), para criar uma espécie de anteparo às eleições que virão em 2022, no Brasil, publicaram uma espécie de tratado de enfrentamento sob o título de "Fake news e eleições. O guia definitivo", com a apresentação auxiliar de ferramentas técnicas e jurídicas.

Longe de ser exaustivo, o panorama acima pretende funcionar, de um lado, como um mostruário da atenção que as fake news estão despertando e, de outro lado, como um indicador de que os problemas e dilemas que as fake news apresentam só tendem a se intensificar com as deepfakes, daí a importância de se tratar sem demora deste tema que está emergindo e que promete trazer danos para o futuro. Variadas definições de deepfakes serão encontradas nos artigos presentes neste número da TECCOGS, dedicado justamente a essa questão. O dossiê não tem a finalidade de antecipar o que os artigos irão discutir, mas apenas levantar o que parece ser a distinção fundamental entre fake news e deepfake e as consequências, ao mesmo tempo, similares, mas, sobretudo, distintas que estes últimos podem trazer. 
Enquanto as fake news têm, na sua grande maioria, uma natureza semiótica verbal, as deepfakes fogem desse domínio para penetrar no reino da visualidade e sonoridade como base para o verbal audível. O primeiro problema que surge diz respeito ao fato de que, até certo ponto, as fake news seguem um padrão composicional que pessoas relativamente bem informadas já conseguem detectar. Alguns dos elementos desse padrão encontram-se, por exemplo, no design pouco sofisticado, tendendo para um sensacionalismo indisfarçável. Enquanto para alguns, isso é gerador de suspeita, de outro lado, para outros, induz credulidade, conforme foi discutido por Beiguelman (2021, p. 276) sobre os designs dos vídeos caseiros que explodiu com o YouTube. Trata-se aí de uma estética que procura se contrapor "ao imaginário tecnicamente perfeito do padrão de qualidade hollywoodiano (ou da Rede Globo)". Dispensando mediações tecnológicas mais sofisticadas, as imagens funcionam "como se fossem decalques do real, sem nenhuma interferência dos meios que a produzem e de quem os instrumentaliza. É nessa idealizada contraposição que reside a eficácia da estética amadora" (ibid.). Levado para as deepfakes, esse é um fator que, longe de gerar suspeita, intensifica a credibilidade.

Em segundo lugar, a natureza assertiva das fake news, sua natureza sempre falseadora em relação àquilo a que se refere, ou seja, os fatos que ela noticia, permite que essa referência seja testada, como o é, pelas organizações de checagem de fatos. Mesmo quando fake news assumem o tom genérico de uma voz proveniente de fontes desconhecidas, como, por exemplo, "celulares dão câncer", embora esse registro de linguagem pareça vir de um oráculo, existem fontes de informação confiáveis em que a afirmação pode ser testada. Diante disso, aonde a distinção em relação às deepfakes aparece?

De acordo com a semiótica, a ação interpretativa de um discurso verbal é muito distinta daquela de um signo visual, em especial quando se trata de um vídeo. Mas, antes do vídeo, retomemos as questões levantadas pela evolução da fotografia. Durante algum tempo, o caráter documental da fotografia foi inquestionável, pois a imagem fotográfica funciona, pretensamente, como um duplo confiável daquilo que ela captura. Trata-se, portanto, do registro de um fragmento de fato existente na realidade. Vem daí o emprego da fotografia no jornalismo, assim como o apreço dos historiadores pelos documentos fotográficos.

Contudo, a partir das manipulações das fotografias pelos programas computacionais, o que se deu a partir dos anos I980, a crença até então relativamente inabalável de que as fotos não poderiam mentir foi colocada em questão (Santaella e Nöth, 20I2). A descrença só tendeu a se intensificar com a introdução de programas cada vez mais sofisticados de manipulação da imagem, extremamente fáceis de colocar em uso. 
Não obstante a suspeita relativa ao caráter documental da fotografia haver sido, até certo ponto, incorporada pela cultura, existe uma questão de base concernente aos processos perceptivos humanos que precisa ser considerada na medida em que afeta justamente a problemática das deepfakes.

A sutilíssima teoria lógica da percepção desenvolvida por C. S. Peirce revela que os julgamentos perceptivos instantâneos, que resultam dos processos perceptivos humanos, são indubitáveis (Santaella, em progresso). Não somos capazes e, portanto, não podemos duvidar daquilo que vemos. Os julgamentos perceptivos só podem mudar quando, por algum motivo, eles são colocados em dúvida, de modo que o processo perceptivo é reencenado para sanar a dúvida. Isso significa que, em primeira instância, não somos capazes de duvidar das deepfakes. Enquanto os signos fotográficos, por serem estáticos, já demonstram o hiato espaço-temporal entre o registro e a realidade que flui e se transforma para além desse registro, no caso dos vídeos, cria-se, a par do indubitável do que os olhos veem, o pacto narrativo que impede a suspensão da crença. Tudo isso funciona como um indicador de que muita campanha educativa terá que ser desenvolvida para que as deepfakes sejam colocadas sob suspeita como necessariamente devem ser.

\section{Referências}

ABBOUD, Georges; NERY JÚNIOR; Nelson; CAMPOS, Ricardo. Fake news e regulação. São Paulo: Thompson Reuters, Revista dos Tribunais, 2018.

BARBOSA, Mariana (org.). Pós-verdade e fake news: reflexões sobre a guerra de narrativas. Rio de Janeiro: Cobogó, 2019.

BEIGUELMAN, Giselle. Políticas da imagem: vigilância e resistência na dadosfera. São Paulo: Ubu, 2021.

BRUNO, Fernanda; ROQUE, Tatiana. A ponta de um iceberg de desconfiança. In: BARBOSA, Mariana (org.). Pós-verdade e fake news: reflexões sobre a guerra de narrativas. Rio de Janeiro: Cobogó, 20I9, p. I3-24.

BUCCI, Eugênio. News não são fake - e fake news não são news. In: BARBOSA, Mariana (org.). Pós-verdade e fake news: reflexões sobre a guerra de narrativas. Rio de Janeiro: Cobogó, 20I9, p. 37-48.

CHATES, Tatiana de Jesus (org.). Perspectivas educacionais em tempos de pós-verdade. Jundiaí: Paco, 2017. 
CURSINO, Carlos; SARGENTINI, Luzmara; PIOVEZANI, Vanice. Discurso e (pós)verdade. São Paulo: Parábola, 202I.

D’ANCONE, Matthew. Pós-verdade: a nova guerra contra os fatos em tempos de fake news. Tradução Carlos Szlak. Barueri: Faro, 20 I8.

DUNKER, Christian; TEZZA, Cristovão; FUKS, Julián; TIBURI, Marcia; SAFATLE, Vladimir. Ética e pós-verdade. Porto Alegre: Dublinense, 2017.

FAUSTINO, André. Fake news: a liberdade de expressão nas redes sociais na sociedade da informação. São Paulo: Lura, 2020.

FERRARI, Pollyana. Como sair das bolhas. São Paulo: Educ, 202I.

Gi. Pós-verdade é eleita a palavra do ano pelo Dicionário Oxford. Globo Notícias, ı6/ıг/20ı6. Disponível em: gi.globo.com/educacao/noticia/ pos-verdade-e-eleita-a-palavra-do-ano-pelo-dicionario-oxford.ghtml.

Acesso em: I2 ago. 202I.

JORGE, Higor Vinicius N.; JORGE JÚNIOR, Hélio Molina; NOVAIS, Kayki; FONSECA, Ricardo Magno T. Fake news e eleições: o guia definitivo. Salvador: JusPODIVM, 202I.

KEYES, Ralph. A era da pós-verdade: desonestidade e enganação na vida contemporânea. Tradução Fábio Creder. Petrópolis: Vozes, 20 I8.

LIMA, Ramalho. Estudo revela que bots espalham fake news massivamente em poucos segundos, 2018. Tecmundo. Disponível em: tecmundo.com.br/internet/136479-estudo-revela-bots-espalham-fakenews-massivamente-segundos.htm. Acesso em: I2 ago. 202I.

MACEDO JÚNIOR, Ronaldo P. Liberdade de expressão ou dever de falar a verdade. In: BARBOSA, Mariana (org.). Pós-verdade e fake news: reflexões sobre a guerra de narrativas. Rio de Janeiro: Cobogó, 2019, p. $79-86$.

MELLO, Patrícia Campos. A máquina do ódio: notas de uma repórter sobre fake news e violência digital. São Paulo: Companhia das Letras, 2020.

MENEZES, Paulo Brasil. Fake news: modernidade, metodologia e regulação. Salvador: JusPODIVUM, 2020.

RAIS, Diogo (org.). Fake news: a conexão entre a desinformação e o direito. São Paulo: Revista dos Tribunais, 2018.

SANTAELLA, Lucia. A pós-verdade é verdadeira ou falsa? São Paulo: Estação das Letras e Cores, 2018. Não somos capazes de duvidar do que vemos. Em progresso.

SERVA, Leão. Jornalismo e desinformação. São Paulo: Senac, 200 I. 